\title{
Development of a Framework for Model Predictive Control (MPC) in a Large-Sized Low-Energy Office Building Using Modelica Grey-Box Models
}

\author{
Svenne Freund, Gerhard Schmitz \\ Institute of Engineering Thermodynamics, Hamburg University of Technology, Germany
}

\begin{abstract}
Model predictive control (MPC) is investigated in a large-sized, low-energy office building. This paper is a first step for implementing MPC in the building and identifies the possible outcomes in energy savings and thermal comfort simulation-based. A framework for parameter identification and optimal control has been developed. Unlike the majority of MPC studies, this study uses grey-box models which are implemented in Modelica which has several advantages. The simulation results suggest an improved comfort level by reducing the occurrence of high temperature peaks and less fluctuating indoor air temperatures. The obtained savings in used heat energy are about $12 \%$ compared to conventional control.
\end{abstract}

\section{Introduction}

Approximately $30 \%$ of the global final energy consumption and more than $55 \%$ of the global electricity demand are related to buildings. The building sector is responsible for nearly $40 \%$ of direct and indirect $\mathrm{CO}_{2}$ emissions and is therefore of major importance for meeting the Paris Agreement goals in 2015. According to these, the average building energy use per person needs to be reduced by at least $10 \%$ by 2025 (International Energy Agency, 2017).

The importance of building heating system control in relation to the energy efficiency of the building is often underestimated. Even in new and modern buildings, inefficient or inadequate control of heating, ventilation and air conditioning (HVAC) systems can significantly increase the energy consumption. Besides the improvement of the building's envelope or the HVAC systems itself by refurbishment or replacement, optimising the building's control system is an attractive and comparatively low-cost way of increasing the energy efficiency, especially for contemporary buildings where the potential of refurbishment measures are limited.

Model predictive control (MPC) is a promising control approach to ensure thermal comfort with minimal energy demand. Several studies have investigated the energy saving potential of MPC in simulations. However, many of these studies only consider test cells or experimental buildings and not a fully operated largesized building. Only few studies exist where MPC was experimentally applied to real operated buildings. Sturzenegger et al. (2016) investigated MPC in a modern office building over a period of seven months and reported energy savings of $17 \%$. Similarly, Široký et al. (2011) applied MPC to a university building consisting of three different blocks and found an energy saving potential of $15 \%$ to $28 \%$ depending on the insulation level of the blocks.

This paper can be seen as a first step to implement MPC in a large-sized low-energy office building. The building offers high potential for investigating and implementing MPC since it is already well equipped with measurement equipment and is mainly heated by radiant slabs with high thermal inertia. The aim of this paper is to obtain the potential energy savings and improvements in thermal comfort as well as exploring possible disadvantages and major challenges. In the course of this work, a framework for parameter identification and optimal control problems has been developed. The framework makes use of grey-box models for thermal zones. Unlike the vast majority of studies, which use linear or nonlinear state-space representations, the here used models are implemented in Modelica (Modelica Association, 2019). The use of equation-based modelling reduces the modelling effort and improves the applicability of MPC and also allows for easy formulation and solution of large scale, nonlinear optimisation problems as described in Wetter et al. (2016).

\section{Office building}

The investigated office building (Figure 1) is located in the city of Hamburg in Northern Germany.

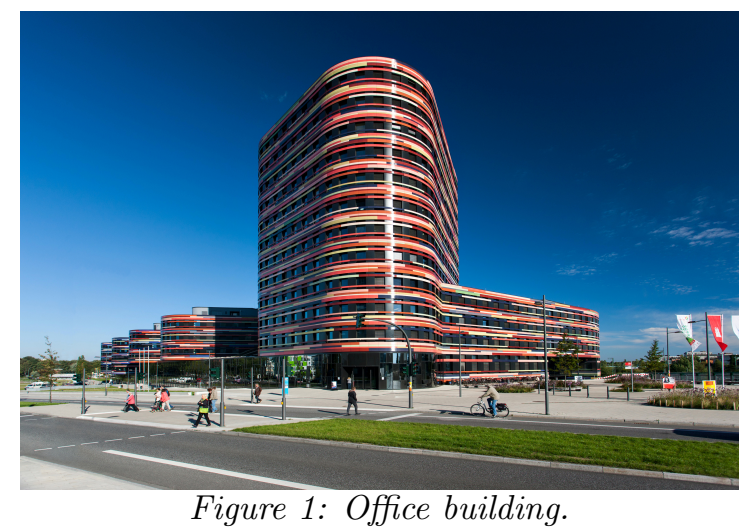


With a gross floor space of $46500 \mathrm{~m}^{2}$, the building provides around 1500 workplaces within 1250 office rooms. Today the building is used as headquarter of the Local Ministry for Energy and Environment and the Ministry for Urban Development and Housing. The building consists of seven low-rise building parts (referred as building A-D and F-H) with five floors and one high-rise building part (building E) with 13 floors. The building was planned and built as a sustainable low-energy building within the framework "Energy Optimised Building Construction" (EnOB) and as part of the International Building Exhibition in 2013. The energetic target values are defined as an annual primary energy demand of less than $70 \mathrm{kWh} /\left(\mathrm{m}^{2} \mathrm{a}\right)$ and a maximum annual heating demand of $15 \mathrm{kWh} /\left(\mathrm{m}^{2} \mathrm{a}\right)$. To examine these objectives and to optimise the building operation, a scientific energy monitoring was implemented in July 2014 and is still in operation. The monitoring results showed that the target for primary energy usage was well met while the heating demand exceeded the planning value by factor two. As part of the monitoring, 32 office rooms serve as reference rooms and were equipped with sensors for, amongst others, room temperature, humidity, presence and window handling to analyse and evaluate thermal comfort. Part of the obtained monitoring data is used in this paper.

\section{Standard office}

It can be distinguished between two basic standard office layouts. The most common layout is the rectangular single office. Besides this, the offices located in the protruding curved building parts have a slightly different geometry with a convex or concave outer facade and are often used as double offices. Each rectangular single office has a width of $2.5 \mathrm{~m}$ and a clear height of $2.89 \mathrm{~m}$. The office's length varies so that the resulting floor space of a rectangular single office ranges from $10 \mathrm{~m}^{2}$ to $13 \mathrm{~m}^{2}$. Each single office has a fully openable window with a glazing area of $2.63 \mathrm{~m}^{2}$ and a weather-proof ventilation flap for manual ventilation. The windows are realised as triple glazing with a heat transfer coefficient of $U_{\mathrm{g}}=0.7 \mathrm{~W} /\left(\mathrm{m}^{2} \mathrm{~K}\right)$. The building's envelope is realised as an unitised facade and consists of several mounted elements with distinctively coloured horizontal ceramic panels as shown in Figure 1. The area of the external wall without glazing is $4.6 \mathrm{~m}^{2}$ for a rectangular single office. According to the manufacturer, the heat transfer coefficient of the element facade is $U_{\mathrm{w}}=0.9 \mathrm{~W} /\left(\mathrm{m}^{2} \mathrm{~K}\right)$.

During winter months, mechanical ventilation is used and the offices are supplied with preheated air. In summer, the offices are manually ventilated by windows and ventilation flaps while the air handling unit (AHU) is not operating. The offices are heated by thermally activated building systems (TABS) which are realised as concrete core activation (CCA) of the office ceilings.

\section{Heating system}

The building's heating system is primarily based on shallow geothermal energy in combination with two electrical heat pumps (nominal thermal power output each: $\dot{Q}_{\mathrm{HP}}=264 \mathrm{~kW}$ ). Additionally, a district heating connection is used for domestic hot water supply as well as peak load coverage (nominal thermal power output: $\dot{Q}_{\mathrm{DH}}=750 \mathrm{~kW}$ ). As previously mentioned, the office rooms are mainly heated by TABS in form of thermo-active ceilings with a maximum supply temperature of $32^{\circ} \mathrm{C}$. Each building part has two different TABS heating circuits which results in 16 separate TABS heating circuits. The supply temperatures of these heating circuits are controlled by a standard linear heating curve using the dynamic average of the outside air temperature for the past 36 hours together with a simple schedule for feeding the TABS.

\section{Model structure and parameter identi- fication}

This section describes the used model structure and the identification process to obtain models which can be used as process models for the MPC. As described later, the MPC uses models of two single offices with different orientations which are supplied by the same TABS heating circuit to control the supply temperature of this heating circuit. The first office (referred to as Office SW) is oriented in south-western direction and has a floor area of $10.22 \mathrm{~m}^{2}$, while the second office (referred to as Office NE) is oriented in northeastern direction and has a floor area of $12.72 \mathrm{~m}^{2}$.

\section{Grey-box model}

Grey-box models have been widely discussed in literature for predictive control strategies. These model types are a trade-off between physical "white-box" models and purely data-driven "black-box" models. Therefore, these models use knowledge about the building physics and model structure and combine it with measured data. Grey-box building models can be represented by networks consisting of thermal resistances and capacitances in analogy to electrical networks. Figure 2 depicts the thermal network of the proposed model. Similar model structures have to be found to give good accuracy for predictive control applications while still being relatively simple (see Berthou et al. (2014) and Harb et al. (2016)). The thermal zone is represented by a grey-box models consisting of three capacitances and four resistances (R4C3 model). The model is extended by a TABS model with one capacitance and two resistances and a resistance for the AHU. The resistances of the AHU and TABS ( $R_{\mathrm{AHU}}$ and $\left.R_{\mathrm{TABS}, 2}\right)$ are adjustable in a way, that the resistance values are set to $R_{\text {off }}=10^{6} \mathrm{~K} / \mathrm{W}$ as long as there is no volume flow or heat flow, respectively. The model has seven inputs in total which are given in Table 1. 


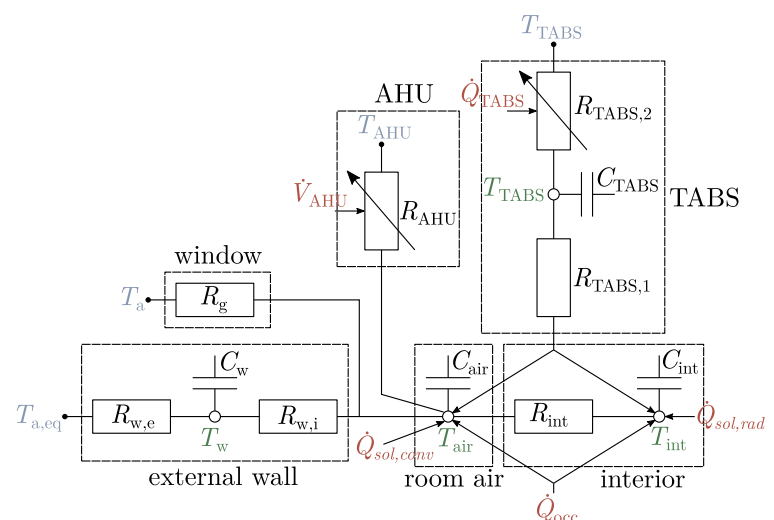

Figure 2: Thermal network representation of the used grey-box model.

Table 1: Description of model inputs.

\begin{tabular}{ll}
\hline Input name & Description \\
\hline$T_{\mathrm{a}}$ & Outdoor temperature $\left[{ }^{\circ} \mathrm{C}\right]$ \\
$T_{\mathrm{AHU}}$ & $\begin{array}{l}\text { Supply temperature of mechanical } \\
\text { ventilation }\left[{ }^{\circ} \mathrm{C}\right]\end{array}$ \\
$\dot{V}_{\mathrm{AHU}}$ & Volume flow rate of AHU, used as \\
& binary signal for $R_{\mathrm{AHU}}\left[\mathrm{m}^{3} / \mathrm{s}\right]$ \\
$T_{\mathrm{TABS}}$ & Supply temperature of TABS $\left[{ }^{\circ} \mathrm{C}\right]$ \\
$\dot{Q}_{\mathrm{TABS}}$ & Heat flow rate of TABS, used as bi- \\
& nary signal for $R_{\mathrm{TABS}}[\mathrm{W}]$ \\
$I_{\mathrm{GH}}$ & Global horizontal irradiance \\
& {$\left[\mathrm{W} / \mathrm{m}^{2}\right] \quad$} \\
$O C C$ & Occupancy signal $[0,1]$ \\
\hline
\end{tabular}

A simplification of the equivalent outdoor temperature according to VDI 6007 (2015) is used to describe the heat exchange between the building exterior and the environment. The equivalent outdoor temperature considers the influence of short-wave radiation, while as a simplification long-wave radiation is neglected:

$$
T_{\mathrm{a}, \mathrm{eq}}=T_{\mathrm{a}}+I_{\mathrm{GH}} \frac{\alpha_{\mathrm{F}}}{\alpha_{\mathrm{A}}}
$$

The short-wave absorption coefficient is chosen to $\alpha_{\mathrm{F}}=0.5$ and the exterior heat transfer coefficient is set to $\alpha_{\mathrm{A}}=25 \mathrm{~W} /\left(\mathrm{m}^{2} \mathrm{~K}\right)$ according to DIN 6496 (2018).

The solar heat gains $\dot{Q}_{\text {sol }}$ are determined by

$$
\dot{Q}_{\mathrm{sol}}=f_{\mathrm{sol}} \cdot I_{\mathrm{GH}}
$$

where $f_{\text {sol }}$ is an empirical factor which is estimated during the identification process. The factor $f_{\text {sol }}$ can be interpreted as an effective window area in which the solar radiation enters. This basic approach for solar gains is assumed to be sufficient for this application since the solar radiation during winter at the buildings' latitude is low and therefore has a small influence on the thermal behaviour. According to DIN 52016 (2018) the convective contribution of solar heat gains can be assumed as $10 \%$. The radiative part only contributes to the inner wall surfaces and does not affect the window itself or the the external wall where the window is built in as described in VDI 6007 (2015).

The internal gains are calculated by multiplying the occupancy signal, which is detected by presence sensors, and a constant internal heat gain $\dot{Q}_{\text {occ }}$ which is part of the identification process. The convective part of internal gains is assumed to be $40 \%$.

The heat flow from the TABS is also split into a convective and radiative part, although according to Sourbron (2012) the convective contribution only accounts for $5 \%$.

The model in Figure 2 is implemented in Modelica and in the course of this work, an interface between these Modelica models and the MATLAB Optimization Toolbox (The MathWorks, 2018) has been developed. This outlined framework supports the parallel execution of Modelica models and therefore achieves a very efficient solving of the resulting optimisation problems.

\section{Identification process}

For MPC applications, the precision and accuracy of the models is crucial for its effectiveness and reliability as shown by Blum et al. (2019). Therefore, the model identification procedure plays an important role for the accuracy of grey-box models. The building is in full operation which makes the parameter identification even more challenging. Due to the occupants' behaviour, significant unmeasured disturbances can be present in the identification input data. Examples for these unmeasured disturbances are the opening of windows and flaps, opening of office doors or presence of more than one person in an office. To address these challenges, the following parameter identification procedure is proposed:

1. Identify all model parameters in an unoccupied period,

2. Determine the most influential parameters via sensitivity analysis,

3. Use identified parameters from step 1 as initial conditions for parameter identification in an occupied period,

4. Identify the most influential model parameters in an occupied period. The other less influential parameters are kept at their initial values.

The objective function to be minimised, is the root mean square error (RMSE) given as:

$$
\operatorname{RMSE}=\sqrt{\frac{1}{N} \sum_{i=1}^{N}\left(T_{\text {air }}(i)-T_{\text {air }}^{*}(i)\right)^{2}}
$$

where $N$ is the number of samples and $T_{\text {air }}-T_{\text {air }}^{*}$ is the difference between the simulated and measured indoor air temperature. To reduce the number of identification parameters, the thermal resistance of the window $R_{\mathrm{g}}$ and the heat capacitance of internal 
air $C_{\text {air }}$ are presumed to be known as these two parameters have a clear physical meaning and a small uncertainty. Therefore, each office has a set of 10 parameters given in Table 2 which have to be estimated. The parameters' lower and upper bounds are mainly obtained from building construction data or, if there is no information available, according to relevant standards. Other parameter bounds are chosen according to a range of physically plausible values. The identification procedure uses a hybrid scheme with a genetic algorithm and pattern search to increase the chance of finding a global minimum.

The results of the first step, the identification during an unoccupied period, are given in Table 3. A period of ten days without occupancy is chosen. For both rooms, the identified models show a very good accuracy with RMSE around $0.1^{\circ} \mathrm{C}$ or below.

As a next step, a sensitivity analysis is performed to identify the influence of each parameter on the indoor air temperature. The method of Morris (1991) is used within the Matlab toolbox for Global Sensitivity Analysis (Pianosi et al., 2015) to obtain the elementary effects. The method is used because it is efficient due to reduced model evaluation. Figure 3 shows the result of the sensitivity analysis by giving the elementary effect of each parameter.

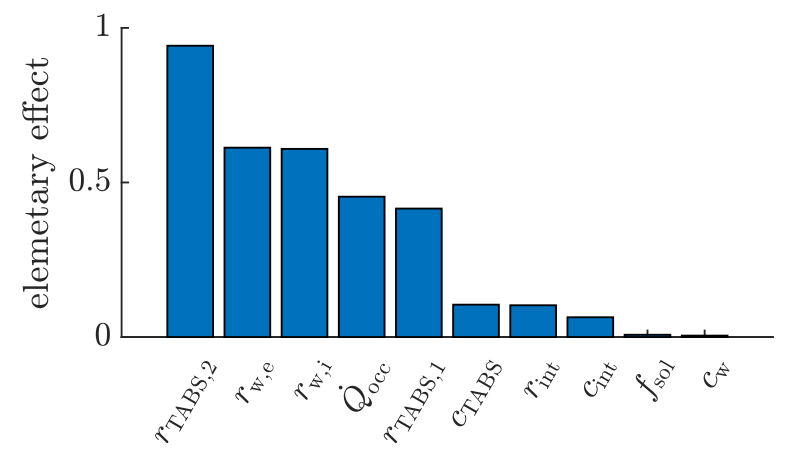

Figure 3: Influence of grey-box parameters with the Morris method.

It can be seen that only five parameters have a significant influence on the model output. Only these five parameters are going to be identified in a next step. A similar procedure was performed by Viot et al. (2018) and improved the quality of their models. Furthermore, this approach makes the identification much more efficient and reduces the chance of over-fitting the models as descibed by Brastein et al. (2018).

A period of 31 days (1 December 2015 to 31 December 2015) is chosen for training data for the occupied period as shown in Figure 4. The identified models are finally validated with data from the period which is later investigated with MPC (1 February 2016 to 28 February 2016). The model inputs for the validation period as well as the model outputs are shown in Figure 5.

The identified models of both offices are in good agreement with the reference measurement in the

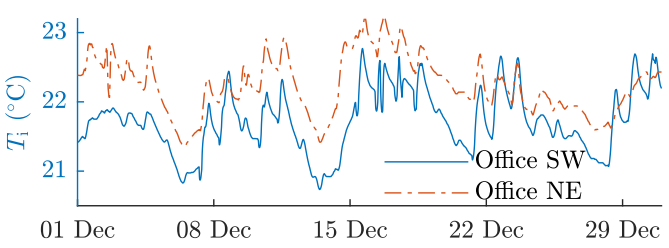

(a) Indoor air temperature.

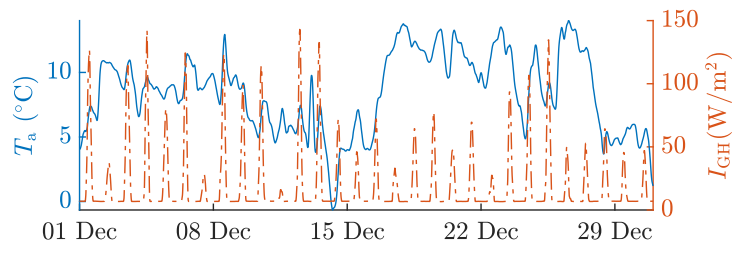

(b) Outdoor air temperature and solar irradiance.

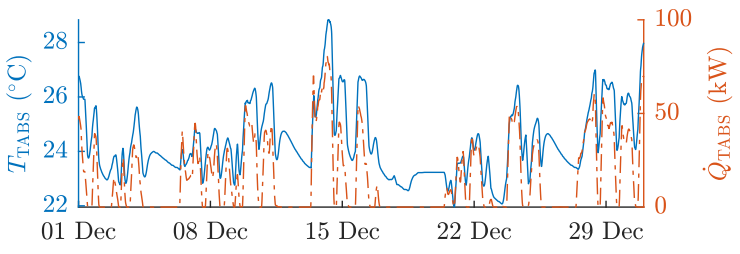

(c) TABS supply temperature and heat flow rate.

Figure 4: Input training data for parameter identification.

training and validation period. The maximum average error occurs during validation in the southwestern office with $0.398^{\circ} \mathrm{C}$. This slightly higher RMSE can be explained by the presence of some outliers as can be seen in Figure 5a. The upwards outliers around the 16 and 25 February probably have been caused by sunlight that directly hit the temperature sensor while the downwards outlier around the 3 February are induced by window or ventilation flap opening. Nevertheless, the office's models are considered as validated and sufficiently accurate for model predictive control applications.

\section{Model predictive control}

The MPC approach is based on constrained optimisation problem. In every control step, the optimisation algorithm minimises a defined objective (or cost) function by choosing an optimal trajectory of the control variable over a given time horizon. A dynamic model is the central part of every MPC. It predicts the future system behaviour depending on the prediction of known inputs and the future control signal which is chosen by the optimisation algorithm. Only the first element of the optimal control variable trajectory is applied to the process. After shifting the time horizon to the next sampling instant, the procedure is repeated with updated data sequences. Therefore, MPC comprises the parts prediction, dynamic optimisation and receding horizon principle.

In this paper, MPC is used to control the supply temperature of a single TABS heating circuit. The controller uses two office models which were identified in the previous section as process models. The solution 
Table 2: Description of grey-box model identification parameters.

\begin{tabular}{|c|c|c|c|c|}
\hline Parameter & Description & Lower bound & Upper bound & Reference \\
\hline$c_{\mathrm{int}}\left[\mathrm{J} /\left(\mathrm{m}^{2} \mathrm{~K}\right)\right]$ & Interior capacitance & $1.1 \cdot 10^{5}$ & $32 \cdot 10^{5}$ & DIN 52016 (2018) \\
\hline$r_{\text {int }}\left[\left(\mathrm{m}^{2} \mathrm{~K}\right) / \mathrm{W}\right]$ & $\begin{array}{l}\text { Interior convective ther- } \\
\text { mal insulance }\end{array}$ & $10^{-4}$ & 0.1 & assumption \\
\hline$c_{\mathrm{w}}\left[\mathrm{J} /\left(\mathrm{m}^{2} \mathrm{~K}\right)\right]$ & External wall capacitance & 4900 & 7250 & construction data \\
\hline$r_{\mathrm{w}, \mathrm{i}}\left[\left(\mathrm{m}^{2} \mathrm{~K}\right) / \mathrm{W}\right]$ & $\begin{array}{l}\text { Thermal insulance of ex- } \\
\text { ternal wall, internal side }\end{array}$ & 0.1 & 1.2 & construction data \\
\hline$r_{\mathrm{w}, \mathrm{e}}\left[\left(\mathrm{m}^{2} \mathrm{~K}\right) / \mathrm{W}\right]$ & $\begin{array}{l}\text { Thermal insulance of ex- } \\
\text { ternal wall, external side }\end{array}$ & 0.1 & 1.2 & construction data \\
\hline$c_{\mathrm{w}}\left[\mathrm{J} /\left(\mathrm{m}^{2} \mathrm{~K}\right)\right]$ & TABS capacitance & $2.5 \cdot 10^{5}$ & $7.3 \cdot 10^{5}$ & construction data \\
\hline$r_{\mathrm{TABS}, 1}\left[\left(\mathrm{~m}^{2} \mathrm{~K}\right) / \mathrm{W}\right]$ & $\begin{array}{l}\text { Thermal insulance of } \\
\text { TABS, room side }\end{array}$ & 0.01 & 1 & $\begin{array}{l}\text { DIN } 6496 \text { (2018) and con- } \\
\text { struction data }\end{array}$ \\
\hline$r_{\mathrm{TABS}, 2}\left[\left(\mathrm{~m}^{2} \mathrm{~K}\right) / \mathrm{W}\right]$ & $\begin{array}{l}\text { Thermal insulance of } \\
\text { TABS, supply side }\end{array}$ & 0.01 & 1 & assumption \\
\hline$\dot{Q}_{\mathrm{occ}}[\mathrm{W}]$ & $\begin{array}{l}\text { Internal gains due to oc- } \\
\text { cupancy }\end{array}$ & 50 & 250 & DIN 18599 (2018) \\
\hline$f_{\mathrm{sol}}[-]$ & Solar gain factor & 0 & 0.5 & assumption \\
\hline
\end{tabular}

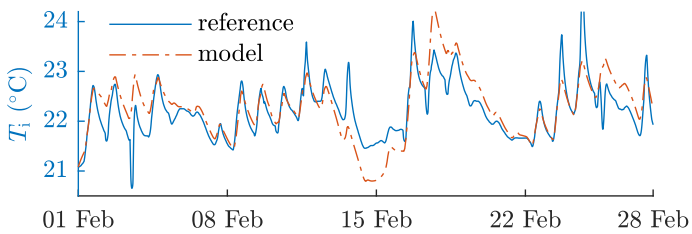

(a) Indoor air temperature of office $S W$.

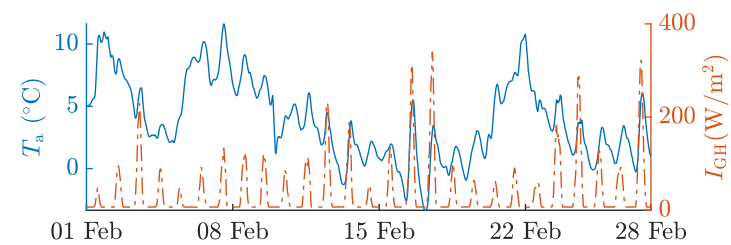

(c) Outdoor air temperature and solar irradiance.

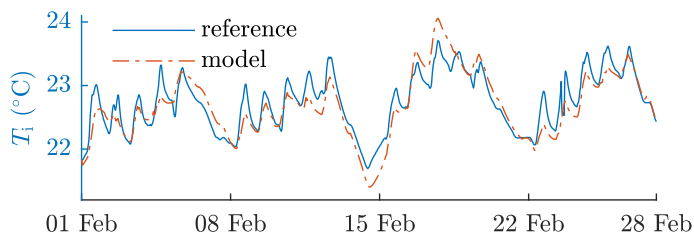

(b) Indoor air temperature of office $N E$.

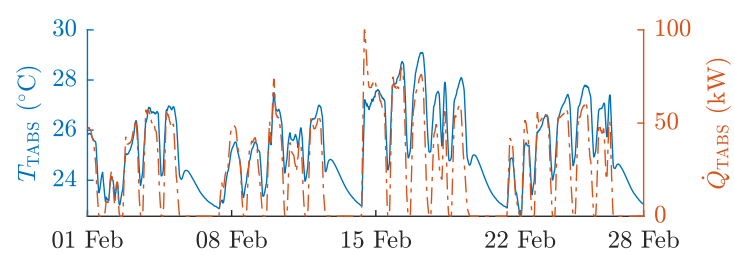

(d) TABS supply temperature and heat flow rate.

Figure 5: Input data for validation and model output.

Table 3: RMSE of training and validation period.

\begin{tabular}{lll}
\hline Dataset & Office & Office \\
& SW & NE \\
\hline Training data, unoccupied & 0.0790 & 0.101 \\
Training data, occupied & 0.188 & 0.232 \\
Validation data & 0.398 & 0.217 \\
\hline
\end{tabular}

of the previously described optimal control problem is applied to an emulator model which emulates the real building. Emulator model and process model are assumed to be identical, meaning that the identified models of the two offices are used as the "real" building. This approach is valid because the error of the indoor air temperature in the considered period is small, see Table 3. After each control step, the process model states have to be initialised for the next optimisation step. This step is called state estimation for which various methods like extended Kalman filter (EKF) or moving horizon state estimation (MHE) exist. In this study, a simple method for state estimation is used. Since process and emulator model are identical, the initial states of the process mod- els are set to the final values of the emulator model states from the previous control step. Furthermore, for each control step the result of the optimisation from the previous control step is used as initial value. The optimisation problem is solved using MATLAB's fmincon with interior point algorithm which is suitable for large-sized non-linear optimisation problems with linear and non-linear inequality constrains (see Byrd et al. (2000) and Waltz et al. (2006) for a more detailed description).

\section{Cost function}

The objective function of the online optimisation problem, which is solved in every control step, is defined by the set of Eqns. (4)-(7).

$$
\min _{u} \alpha \cdot J_{\mathrm{c}}+\beta \cdot J_{\mathrm{e}}
$$

subject to:

$$
\begin{aligned}
& F(\dot{x}(t), x(t), u(t), t)=0 \\
& u_{\min } \leq u(t) \leq u_{\max } \\
& \left|u\left(t+t_{\mathrm{c}}\right)-u(t)\right|<\Delta_{u_{\max }}
\end{aligned}
$$


Table 4: Main parameters of MPC problem.

\begin{tabular}{lll}
\hline Parameter & Description & Value \\
\hline$y_{\text {set }}\left[{ }^{\circ} \mathrm{C}\right]$ & Set point temperature & 22 \\
$\Delta_{y_{\text {set }}}\left[{ }^{\circ} \mathrm{C}\right]$ & Dead band of set point temperature & 0.5 \\
$t_{\mathrm{p}}[\mathrm{h}]$ & Prediction horizon & 48 \\
$t_{\mathrm{c}}[\mathrm{h}]$ & Control horizon & 1 \\
$u_{\min }\left[{ }^{\circ} \mathrm{C}\right]$ & Lower limit of TABS supply temperature & 22 \\
$u_{\max }\left[{ }^{\circ} \mathrm{C}\right]$ & Upper limit of TABS supply temperature & 32 \\
$\Delta_{u_{\max }}\left[{ }^{\circ} \mathrm{C} / \mathrm{h}\right]$ & Maximum slope of TABS supply temperature & 4 \\
$t_{\text {occ,start }}, t_{\mathrm{occ}, \text { end }}$ & Occupancy time & 7 a.m. to 6 p.m. \\
\hline
\end{tabular}

The objective function consists of two parts: a cost function for discomfort $J_{\mathrm{c}}$ and a cost function for energy usage $J_{\mathrm{e}}$. The two different parts can be weighted by the tuning parameters $\alpha$ and $\beta$. Eqn. (5) describes the model dynamics in the form of a differential-algebraic system of equations. The control variable $u(t)$, which is the TABS supply temperature, is constrained by lower and upper limits $\left(u_{\min }\right.$ and $\left.u_{\max }\right)$ as well as by a maximum rate of change $\Delta_{u_{\max }}$. The energy cost function is defined as the heating energy, which is supplied to every zone $i$, by integrating the heat flow rate over the prediction horizon $t_{\mathrm{p}}$ :

$$
J_{\mathrm{e}}=\sum_{i=1}^{n_{\text {zone }}} \int_{0}^{t_{\mathrm{p}}} \dot{Q}_{i, \text { zone }} \mathrm{d} t
$$

The cost function for discomfort consists of two different parts:

$$
J_{\mathrm{c}}=\sum_{i=1}^{n_{\text {zone }}} \int_{0}^{t_{\mathrm{p}}} f_{\mathrm{c}, i}(t) \cdot f_{\mathrm{occ}}(t) \mathrm{d} t
$$

The first part $f_{\mathrm{c}, \mathrm{i}}(t)$ determines the discomfort cost due to violation of the set point:

$$
f_{\mathrm{c}, i}(t)= \begin{cases}0 & \text { if } e(t)<\Delta_{y_{\mathrm{set}}} \\ \gamma \cdot\left(e(t)-\Delta_{y_{\mathrm{set}}}\right) & \text { otherwise }\end{cases}
$$

where $e(t)=\left|y_{i}(t)-y_{\text {set }}\right|$ is the difference between the predicted indoor air temperature of zone $i y_{i}(t)$ and the set point $y_{\text {set }}, \Delta_{y_{\text {set }}}$ is the dead band width and $\gamma$ is a tuning parameter. The second part $f_{\text {occ }}(t)$ describes the occupancy schedule:

$$
f_{\mathrm{occ}}(t)= \begin{cases}1 & \text { if } t \epsilon\left[t_{\mathrm{occ}, \mathrm{start}}, t_{\mathrm{occ}, \mathrm{end}}\right] \\ 0 & \text { otherwise }\end{cases}
$$

where $t_{\text {occ,start }}$ and $t_{\text {occ,end }}$ describe the building occupancy time. The given formulation of the discomfort cost function means that there is a constant set-point for the indoor air temperature during building occupancy time while the temperature is free-floating without a lower limit during non-occupancy time. This approach is chosen since the building's inertia is quite high and the building dynamics are therefore slow so that the indoor air temperature is not expected to drop below a critical level during nonoccupancy time. The description and values of the main MPC parameters are summarised in Table 4 . Furthermore, by using historical measurement data, the prediction of input disturbances is assumed to be perfect.

\section{Results and Discussion}

Figure 6 shows the simulation results for February 2016. The Figures $6 \mathrm{a}$ and $6 \mathrm{~b}$ depict the indoor air temperature of the emulator model under conventional control (red dashed line) and MPC (blue dotdashed line) for the considered offices. Additionally, the set-point temperature (black solid line) during occupancy is shown in black. Figure 6c shows the TABS supply temperature set-point which is the control trajectory generated by MPC controller.

The two control strategies are assessed and compared in terms of comfort and energy usage. Comfort is evaluated by calculating the averaged indoor air temperature and the cumulated violation of the set-point temperature range during building operation. The total heat demand of both offices is used as a benchmark for the energy usage. Table 5 shows the result of the comparison.

As can be seen in Figure $6 \mathrm{a}$ and $6 \mathrm{~b}$, the mean temperature during occupancy is lower in both offices with MPC compared to the conventional control. The mean temperature in the south-western office decreases from $22.4^{\circ} \mathrm{C}$ to $21.6^{\circ} \mathrm{C}$ while the temperature in the north-eastern office reduces from $22.8^{\circ} \mathrm{C}$ to $21.7^{\circ} \mathrm{C}$. Therefore, the MPC controls both rooms as expected close to the lower bound of $21.5^{\circ} \mathrm{C}$. Furthermore, the indoor air temperatures of both offices are more equalised and less fluctuating. As shown in Figures $6 \mathrm{a}$ and $6 \mathrm{~b}$, considerable high temperatures of up to $24^{\circ} \mathrm{C}$ occur with conventional control, most conspicuous in the week from 15 to 22 February. These high temperatures result from a combination of high TABS supply temperatures and high solar gains as can be seen in Figures $5 \mathrm{c}$ and $5 \mathrm{~d}$. The high supply temperatures are generated by the heating curve and therefore can be traced back to the low outdoor air temperature as shown in Figure 5c. Due to the predictive behaviour, the MPC is able to ensure the 


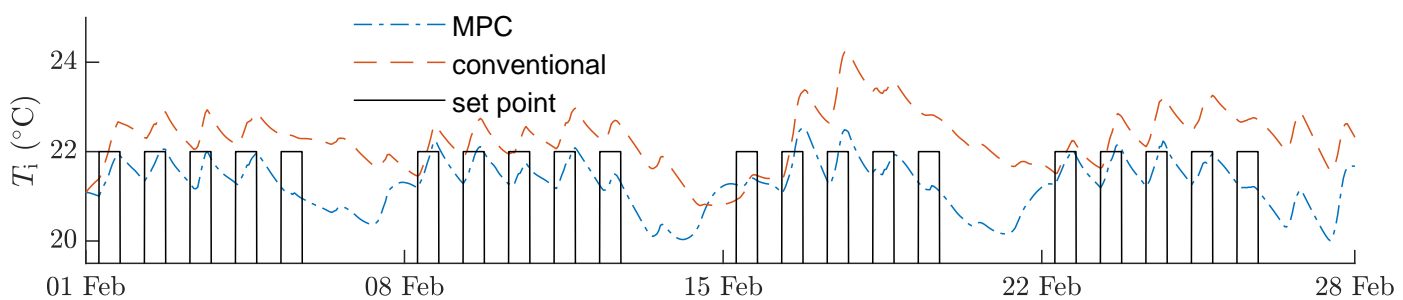

(a) Indoor air temperature of office $S W$.

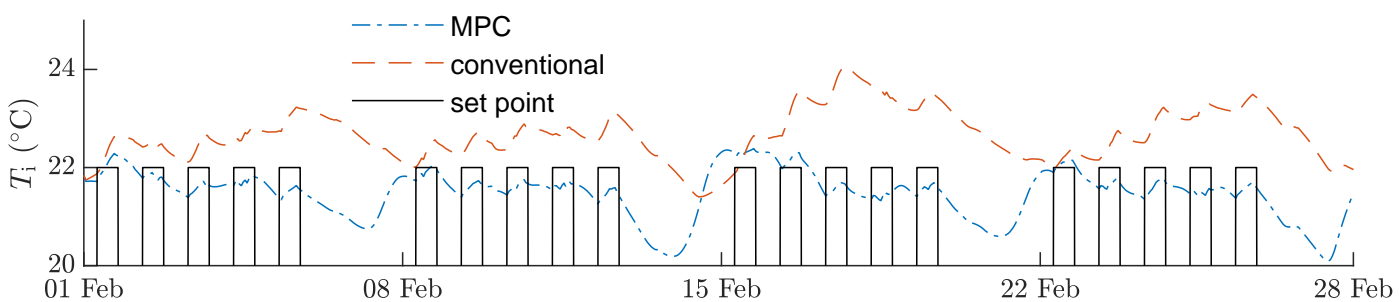

(b) Indoor air temperature of office $N E$.

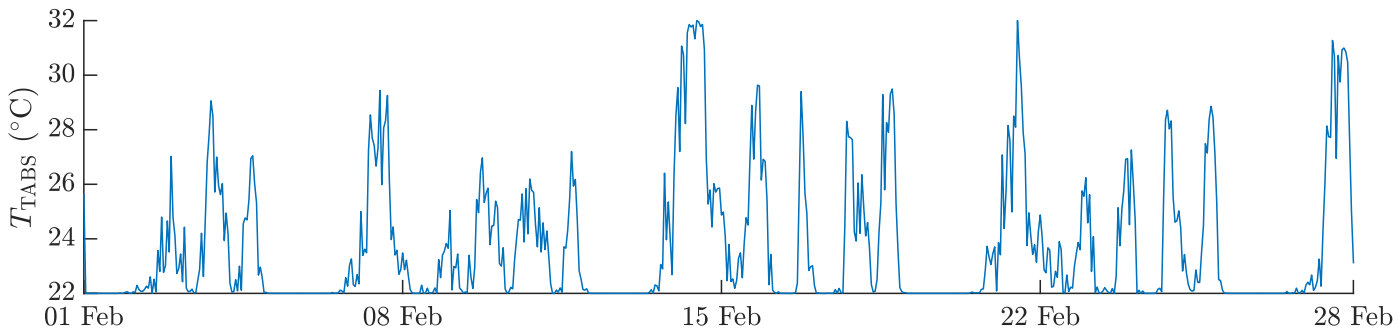

(c) TABS supply temperature with $M P C$.

Figure 6: Simulation results and comparison of MPC with conventional control.

Table 5: Comparison of conventional control and MPC in terms of comfort and energy usage.

\begin{tabular}{|c|c|c|c|c|c|}
\hline & \multirow{2}{*}{ Total heat demand $(\mathrm{kWh})$} & \multicolumn{2}{|r|}{ Office SW } & \multicolumn{2}{|r|}{ Office NE } \\
\hline & & $\bar{T}_{\mathrm{i}}\left({ }^{\circ} \mathrm{C}\right)$ & Cumul. viol. (Kh) & $\bar{T}_{\mathrm{i}}\left({ }^{\circ} \mathrm{C}\right)$ & Cumul. viol. (Kh) \\
\hline Conventional & 113 & 22.4 & 57.7 & 22.8 & 93.7 \\
\hline $\mathrm{MPC}$ & 99 & 21.6 & 28.5 & 21.7 & 3.56 \\
\hline
\end{tabular}

prescribed set-point resulting in a significantly lower indoor air temperature in this period of time. The MPC is therefore considerably better in adapting to changing weather conditions.

The high indoor air temperatures with conventional control result in a high violation of the upper setpoint temperature bound of $22.5^{\circ} \mathrm{C}$. As given in Table 5 , the cumulative set-point violation decreases significantly for both offices with MPC. This can mainly be ascribed to the reduction of the indoor air temperature. The MPC controller therefore manages to keep the room temperature within the prescribed range in most cases during the occupancy time. However, as can be seen in Figures $6 \mathrm{a}$ and $6 \mathrm{~b}$, the room temperatures often reach the prescribed set point quite late on a working day. The temperatures in the morning hours are mostly close to the lower bound or even slightly below. This indicates that there is still potential for optimising the MPC by adjusting relevant tuning parameters.

As given in Table 5, the heat supplied to the offices is reduced by $12 \%$ with MPC. However, these results can only be interpreted as the savings of used heat energy and not of final energy. Furthermore, these energy savings are obtained by controlling only one of the eight building parts with MPC. To gain a more generalised result, it is necessary to extend the approach to the other parts as well. To obtain the final energy savings, a model of the building heating system would have to be coupled to the thermal zone models. The development of a building heating system model in Modelica is part of the ongoing work. The reduction of energy demand can therefore only be restrictedly compared to the results of other studies. Nevertheless, considering that the building is characterised as a modern and energy efficient building the results are comparable.

\section{Conclusion}

This work has investigated the potential of predictive control strategies in terms of energy savings and comfort in a contemporary and energy efficient office building. The results show that the useful en- 
ergy savings are about $12 \%$ compared to the conventional heating curve based control strategy. Significant improvements were found regarding thermal comfort mainly by reducing high temperature peaks and less fluctuating air temperatures. In order to further confirm these results, it would be necessary to perform simulations of one or more complete heating periods. Furthermore, the approach should be tested in other building parts. In addition, the here used approach of describing thermal comfort could be extended by considering further comfort parameters like relative humidity. To obtain the final energy savings, a model of the entire building heating system is currently developed. Eventually, it is planned to implement the developed MPC approach in part of the building and investigate the performance experimentally.

\section{References}

Berthou, T., P. Stabat, R. Salvazet, and D. Marchio (2014). Development and validation of a gray box model to predict thermal behavior of occupied office buildings. Energy and Buildings 74, 91-100.

Blum, D. H., K. Arendt, L. Rivalin, M. A. Piette, M. Wetter, and C. T. Veje (2019). Practical factors of envelope model setup and their effects on the performance of model predictive control for building heating, ventilating, and air conditioning systems. Applied Energy 236, 410-425.

Brastein, O. M., D. Perera, C. Pfeifer, and N.-O. Skeie (2018). Parameter estimation for grey-box models of building thermal behaviour. Energy and Buildings 169, 58-68.

Byrd, R. H., J. C. Gilbert, and J. Nocedal (2000). A trust region method based on interior point techniques for nonlinear programming. Mathematical Programming 89(1), 149-185.

DIN 18599 (2018). Energy efficiency of buildings Calculation of the net, final and primary energy demand for heating, cooling, ventilation, domestic hot water and lighting - Part 10: Boundary conditions of use, climatic data (DIN 18599).

Deutsches Institut für Normung (2018). Energy performance of buildings - Energy needs for heating and cooling, internal temperatures and sensible and latent heat loads - Part 1: Calculation procedures (ISO 52016).

Deutsches Institut für Normung (2018). Building components and building elements - Thermal resistance and thermal transmittance - Calculation methods (ISO 6946).

Harb, H., N. Boyanov, L. Hernandez, R. Streblow, and D. Müller (2016). Development and validation of grey-box models for forecasting the thermal response of occupied buildings. Energy and Buildings 117, 199-207.

International Energy Agency (2017). Energy Technology Perspectives 2017: Catalysing Energy Technology Transformations.

Modelica Association (2019). Modelica language specification, version 3.4. https://modelica.org.

Morris, M. D. (1991). Factorial Sampling Plans for Preliminary Computational Experiments. Technometrics 33, 161-174.

Pianosi, F., F. Sarrazin, and T. Wagener (2015). A Matlab toolbox for Global Sensitivity Analysis. Environmental Modelling \&S Software 70, 80-85.

Široký, J., F. Oldewurtel, J. Cigler, and S. Prívara (2011). Experimental analysis of model predictive control for an energy efficient building heating system. Applied Energy 88(9), 3079-3087.

Sourbron, M. (2012). Dynamic thermal behaviour of buildings with concrete core activation. Ph. D. thesis, Leuven.

Sturzenegger, D., D. Gyalistras, M. Morari, and R. S. Smith (2016). Model Predictive Climate Control of a Swiss Office Building: Implementation, Results, and Cost-Benefit Analysis: Implementation, Results, and Cost-Benefit Analysis. IEEE Transactions on Control Systems Technology 24(1), 1-12.

The MathWorks (2018). Matlab optimization toolbox 2018a. https://mathworks.com/products/ optimization.html.

Verein Deutscher Ingenieure (2015). Calculation of transient thermal response of rooms and buildings: Modelling of rooms (VDI 6007).

Viot, H., A. Sempey, L. Mora, J. C. Batsale, and J. Malvestio (2018). Model predictive control of a thermally activated building system to improve energy management of an experimental building: Part I - Modeling and measurements. Energy and Buildings 172, 94-103.

Waltz, R. A., J. L. Morales, J. Nocedal, and D. Orban (2006). An interior algorithm for nonlinear optimization that combines line search and trust region steps. Mathematical Programming 107(3), 391-408.

Wetter, M., M. Bonvini, and T. S. Nouidui (2016). Equation-based languages - A new paradigm for building energy modeling, simulation and optimization. Energy and Buildings 117, 290-300. 